\title{
Tavuk gübresi ve fertigasyon EC'lerinin örtüaltı baharlık domates (Solanum lycopersicum) yetiştiriciliğinde verim ve kalite üzerine etkileri
}

\section{Effects of chicken manure and fertigation ECs on yield and quality in greenhouse spring tomato (Solanum lycopersicum) cultivation}

\author{
Nermin ATA®, Mustafa KAPLAN \\ Akdeniz Üniversitesi, Ziraat Fakültesi, Toprak Bilimi ve Bitki Besleme Bölümü, 07070, Antalya \\ Sorumlu yazar (Corresponding author): M. Kaplan, e-posta (e-mail): mkaplan@akdeniz.edu.tr \\ Yazar(lar) e-posta (Author e-mail): nrmnata7@gmail.com
}

\section{MAKALE BILGISII}

Alınış tarihi 26 Ekim 2020

Düzeltilme tarihi 09 Kasım 2020

Kabul tarihi 09 Kasım 2020

\section{Anahtar Kelimeler:}

Domates

Tavuk gübresi

Fertigasyon EC'si

Örtüalt1

\begin{abstract}
ÖZ
Bu çalışma, tavuk gübresi (TG) ile fertigasyon (FRT) elektriksel iletkenlik (EC)'lerinin (FRT.EC) ve bunların interaksiyonlarının, örtüaltı baharlık domates (Solanum lycopersicum L.) yetiștiriciliğinde meyve verimi, kalitesi ve bitki beslenmesi üzerine etkilerini belirlemek amacıyla gerçekleştirilmiştir. TG uygulamalarının, toprak EC değeri, organik madde, toplam azot, alınabilir çinko ve alınabilir bor kapsamı üzerine etkileri önemli bulunmuş̧ur. FRT.EC'si uygulamaları toprak EC değeri, toplam azot ve değişebilir potasyum içeriği üzerine istatistiksel olarak önemlidir. Bitki analiz sonuçlar incelendiğinde; TGxFRT.EC interaksiyonun toplam potasyum üzerine, FRT.EC'sinin toplam demir üzerine etkileri istatistiksel olarak önemlidir. Meyve besin içeriklerine bakıldığında, TG'si ve FRT.EC'si uygulamalarının toplam magnezyum, TG'si uygulamalarının toplam azot konsantrasyonu üzerine etkileri istatistiksel olarak önemli bulunmustur. Meyve kalite kriterlerinde, TG'si uygulamasının meyve eti sertliği üzerine, TGxFRT.EC interaksiyonunun verim ve meyve sayısı üzerine etkileri istatistiksel olarak önemli bulunmuştur. TGxFRT.EC interaksiyonu çiçek burnu cürüklüğü (BER) gösteren meyve sayısı ve BER ağırlığı üzerine etkileri istatistiksel olarak önemli bulunup, en fazla BER sayısı ve en yüksek BER ağırlığı, $\mathrm{TG}_{400} \mathrm{~kg} \mathrm{da}^{-1}+\mathrm{FRT}$.EC $\mathrm{C}_{3}$ uygulamasında görülmektedir. Çalışma süresi sonunda gübre peletlerinin önemli ölçüde fiziksel olarak sağlam kalabildiği gözlemlenmiștir. Bu gözlem pelet tavuk gübrelerinin ilk yetiştirme periyodundak etkilerini sınırlayabilecek önemli bir faktör olarak düşünülebilir. Tavuk gübresinin önceden uygulanamadığı veya kısa yetiştirme periyoduna sahip bitkilerin yetiştiriciliğinde, pelet yerine toz tavuk gübresi șeklindeki uygulamaların daha doğru bir seçenek olduğu önerilebilir. Bu kapsamda yeni çalışmaların yapılması gereklidir.
\end{abstract}

\section{ARTICLE INFO}

Received 26 October 2020

Received in revised form 09 November 2020 Accepted 09 November 2020

\section{Keywords:}

Tomato

Poultry manure

Fertigation ECs

Greenhouse

\begin{abstract}
This study was conducted to determine the effects of poultry manure (PM) applied with fertigation ECs (F.EC) and their interactions on fruit yield, quality and plant nutrition in greenhouse spring tomato cultivation. Effects of applications of poultry manure on soil EC value, organic matter, total nitrogen, available zinc, available boron content were statistically significant. Fertigation EC is statistically significant on soil EC value, total nitrogen and exchangeable potassium content of soil. When the plant analysis results are examined; poultry manure and fertigation EC interaction on total potassium and fertigation EC applications on total iron are statistically significant. When the fruit nutrient contents examined, poultry manure and fertigation EC on total magnesium and poultry manure on total nitrogen were statistically significant. In the fruit quality criteria, poultry manure was statistically significant on fruit flesh hardness, poultry manure and fertigation EC interaction on yield and fruit number are statistically significant. Poultry manure and fertigation EC interaction was statistically significant on fruit showing Blossom End Rot (BER) number and BER weight and the highest BER number and BER weight was observed in $\mathrm{PM}_{400} \mathrm{~kg} \mathrm{da}^{-1}+\mathrm{F} \mathrm{EC}_{3}$ application. It has been observed that manure pellets are considerably physically stable. This observation can be considered important factor that could limit the effects of pellet poultry manure on the first growing period. In the cultivation of plants where poultry manure cannot be applied before or with a short growing period, applications in the form of powder instead of pellets can be recommended as a more effective option. In this context, new studies are required.
\end{abstract}




\section{Giriş}

Dünya domates (Solanum lycopersicum L.) üretiminde Türkiye \%7.2'lik pay ile 4. sırada yer almaktadır (FAO 2018). Türkiye'de 2017 verilerine göre 30 milyon tondan daha fazla sebze üretilmiştir. Üretilen toplam sebze içerisinde 12.75 milyon ton üretim miktarı ile domates ilk sırada yer almaktadır. Türkiye domates üretiminin yıllara göre değişmekle birlikte, \%68-72'i açıkta, \%28-32'i ise örtüaltında yapılmaktadır (Güvenç 2019).

Organik materyallerin, toprağı korunması ve geliştirilmesindeki çok yönlü katkısı bilinmektedir. Buna rağmen bu tür gübrelerin kullanımı beklenilen düzeyin çok altındadır (Demirtaş ve ark. 2012). Ülkemiz toprakları organik madde içeriği yönünden bazı alanlar hariç genellikle fakirdir (Dinç ve ark. 2001). Ülkemizde, başta Orta Anadolu Bölgesi olmak üzere birçok bölgede toprakların organik madde kapsamları \%2'nin hatta \%1'in altına düşmüştür (Şeker ve Karakaplan 1999). Bu durumda her türlü bitkisel ve hayvansal atığın fiziksel, kimyasal ve biyolojik özellikleri iyileştirilip (kompostlanarak) tarımda geri kullanımı sağlanarak, bitkisel üretimdeki organik madde talebi dönemsel değil sürekli olarak karşılanabilmelidir. $\mathrm{Bu}$ amaçla katı ve sıvı organik gübreler kullanılmaktadır (Kalkan ve ark. 2017). Bu ihtiyacın karşılanmasında, bitki besin elementi içeriği ve toprak düzenleyici etkisi yüksek olan, bol miktarda, sürekli olarak üretilen ve üretimi her geçen gün artan tavuk gübresi, değerlendirilmesi gereken alternatiflerden biri olarak ele alınmalıdır (Kaplan ve Maltaş 2016).

Ülkemiz tavukçuluk sektöründe yaklaşık 14 bin 360 adet etlik piliç kümesi, 3 bin 141 adet ticari yumurta üretimi yapan kümes ve 2 bin 237 adet damızlık kümes olmak üzere toplam 19 bin 738 adet kümeste tavuk üretimi yapılmakta ve yıllara göre değişmekle birlikte yaklaşık 5.5 milyon ton $\mathrm{yll}^{-1}$ yaş tavuk gübresi üretilmektedir (Kaplan ve Maltaş 2016). Tavuk gübresi, toprağın organik maddesini ve gübre gereksinimini gidermek amacıyla tarımda uzun süredir kullanılmaktadır. Tavuk gübresinin tarımsal üretimde doğru şekilde kullanılmaması, bazı sorunlara yol açabilmektedir. Tavuk gübresinin yüksek tuz içermesi kullanımını azaltan en önemli unsurlardan birisidir (Korkmaz ve ark. 1996).

Ülkemizde önemli düzeyde üretimi gerçekleştirilen tavuk yetiştiriciliğinin ve dolayısıyla meydana gelen atığın değerlendirilmesi ve tarımsal üretimde açığa çıkan farklı atıkların yarattı̆̆ı çevre kirliliği sorununa çözüm üretmek için mevcut kaynakları değerlendirmek gerekmektedir. (Şensoy ve ark. 1996).

Toprak verimliliği üzerine önemli katkılarda bulunan ve sonrasinda da bitkisel üretimde verim ve kalitenin yükseltilmesini sağlayan toprak organik madde düzeyini artırmanın yollarından bir tanesi de tavuk gübresi kullanımıdır. Bu çalışmada, farklı elektriksel iletkenlik (EC) dozları ile farklı düzeydeki tavuk gübresi uygulamalarının etkileri araştırılmıştır. Bir atık materyal olarak görülen ve iyi yönetilmediği durumda bertaraf edilmesi sakıncalı, depolanması durumunda çevre sağlığı açısından sorun olabilecek ancak tarımda kullanılması durumunda ise oldukça faydalı olan bu organik kaynağın örtüaltı tarımında kullanılmasının erken baharlık domates yetiştiriciliğindeki bitki ve toprağa olan etkileri belirlenmiştir.

\section{Materyal ve Yöntem}

Bu araştırma Akdeniz Üniversitesi Ziraat Fakültesi'ne ait Araştırma ve Uygulama seralarında 2017 yılında yürütülmüştür. Çalışma yapılan sera toprağının özellikleri Çizelge 1'de verilmiştir.

Çizelge 1. Denemede kullanılan toprağın özellikleri.

Table 1. Soil features in treatment.

\begin{tabular}{|c|c|c|}
\hline Özellikler & Değer & Değerlendirme \\
\hline $\mathrm{pH}$ & 7.42 & Hafif alkali reaksiyon \\
\hline Kireç (\%) & 17.2 & Çok yüksek kireçli \\
\hline Kum $(\%)$ & 22.12 & \\
\hline Kil (\%) & 37.88 & Killi tın \\
\hline Silt (\%) & 40.00 & \\
\hline $\mathrm{EC}\left(\mathrm{dS} \mathrm{m}^{-1}\right)$ & 0.42 & Tuzsuz \\
\hline Organik Madde (\%) & 2.43 & Az humuslu \\
\hline Toplam azot (\%) & 0.15 & Çok iyi \\
\hline Allnabilir $\mathrm{P}_{2} \mathrm{O}_{5}\left(\mathrm{mg} \mathrm{kg}^{-1}\right)$ & 236 & Yüksek \\
\hline Değişebilir K (me $\left.100 \mathrm{~g}^{-1}\right)$ & 0.67 & Yüksek \\
\hline Değişebilir $\mathrm{Mg}\left(\mathrm{me} 100 \mathrm{~g}^{-1}\right)$ & 3.88 & İyi \\
\hline Değişebilir Ca (me $\left.100 \mathrm{~g}^{-1}\right)$ & 31.36 & İyi \\
\hline Değişebilir Na (me $\left.100 \mathrm{~g}^{-1}\right)$ & 0.101 & Çok düşük \\
\hline Alınabilir Fe (mg kg $\left.{ }^{-1}\right)$ & 4.73 & İyi \\
\hline Alınabilir $\mathrm{Mn}\left(\mathrm{mg} \mathrm{kg}^{-1}\right)$ & 10.7 & Yeterli \\
\hline Alınabilir $\mathrm{Zn}\left(\mathrm{mg} \mathrm{kg}^{-1}\right)$ & 9.24 & İyi \\
\hline Alınabilir $\mathrm{Cu}\left(\mathrm{mg} \mathrm{kg}^{-1}\right)$ & 6.8 & Yeterli \\
\hline
\end{tabular}

$\mathrm{Bu}$ çalışmada ülkemizde en çok yetiştiriciliği yapılan domates bitkisinin beslenmesi üzerine 3 farklı dozda $\left(0 \mathrm{~kg} \mathrm{da}^{-1}\right.$, $600 \mathrm{~kg} \mathrm{da}^{-1}, 1200 \mathrm{~kg} \mathrm{da}^{-1}$ ) toprağa uygulanan tavuk gübresi ve 2 farklı elektriksel iletkenlik (EC) düzeyine sahip fertigasyon (1.5 $\mathrm{dS} \mathrm{m}^{-1}, 3.0 \mathrm{dS} \mathrm{m}^{-1}$ ) çözeltilerinin ve bunların interaksiyonlarının örtüaltı baharlık domates yetiştiriciliğinde bitki beslenmesi, meyve verimi ve kalitesi üzerine etkileri araştırılmıştır. Kullanılan tavuk gübresi ticari bir ürün olup içeriği Çizelge 2'de verilmiş̧ir.

Çizelge 2. Denemede kullanılan tavuk gübresinin bazı özellikleri.

Table 2. Chicken manure features in treatment.

\begin{tabular}{lc}
\hline Özellikler & Değer \\
\hline Toplam organik madde $(\%)$ & 55 \\
Toplam azot $(\%)$ & 2 \\
Organik azot $(\%)$ & 1 \\
Toplam $\mathrm{P}_{2} \mathrm{O}_{5}(\%)$ & 3 \\
Maksimum nem $(\%)$ & 20 \\
pH & $6-8$ \\
\hline
\end{tabular}

Çalışmada bitki materyali olarak Tayfun $\mathrm{F}_{1}$ domates çeşidi kullanılmıştır. Deneme tesadüf parselleri deneme desenine göre 3 tekerrürlü olarak planlanmış ve her parselde 34 bitki olacak şekilde dikilmiştir. Fideler sıra aras $40 \mathrm{~cm}$, sıra üzeri $90 \mathrm{~cm}$ olacak şekilde deneme parsellerine dikilmiş, dikimden sonraki bütün kültürel işlemler (sulama, ilaçlama vb.) tüm uygulama parsellerine aynı şekilde yapılmıştır.

Denemede yaprak ve meyve örnekleri alınarak gerekli fiziksel ölçümler yapıldıktan sonra laboratuvara getirilmiş, yıkandıktan sonra $65^{\circ} \mathrm{C}$ 'de sabit ağırlığa gelinceye kadar kurutulduktan sonra öğütülerek analize hazır hale getirilmiştir (Kacar ve İnal 2008). 
Bitki analizleri için ise domates yaprak örneklerinde toplam $\mathrm{N}$ modifiye Kjeldahl yöntemine göre belirlenmiştir (Kacar ve İnal 2008). Ayrica, $\mathrm{P}, \mathrm{K}, \mathrm{Ca}, \mathrm{Mg}, \mathrm{Fe}, \mathrm{Mn}, \mathrm{Zn}$ ve $\mathrm{Cu}$ analizleri için bitki örnekleri yaş yakılıp ICP-OES cihazında okunmuştur (Kacar ve İnal 2008). Toprak örneklerinde pH (Jackson 1967), kireç $\left(\mathrm{CaCO}_{3}\right)$ (Evliya 1964), elektriksel iletkenlik (Bower ve Wilcox 1965), bünye (Bouyoucos 1955), organik madde (Black 1965), toplam N (Black 1957), alınabilir P (Olsen ve Sommer 1982), ekstrakte edilebilir K, Ca ve Mg (Kacar 1972) ve alınabilir $\mathrm{Fe}, \mathrm{Zn}, \mathrm{Cu}$ ve $\mathrm{Mn}$ analizleri (Lindsay ve Norwell 1978) yapılmıştır. Domates meyvelerinde ortalama meyve çapı, bitki başına meyve sayısı, ortalama meyve ağırlığı, bitki başına verim değerleri tespit edilmiştir. Çalışmada ayrıca meyvelerin renk, suda çözünebilir kuru madde (SÇKM) miktarı, titre edilebilir asit (TEA) değeri ve meyve suyu pH'sı içeriği belirlenmiştir.

Domateslerde SÇKM miktarı belirlemek üzere meyve örnekleri katı meyve sıkacağından geçirilmiş ve meyve usaresi elde edilmiştir. Bu süzüntüden alınan örnek dijital refraktometre ile belirlenmiştir. Sonuçlar \% olarak ifade edilmiştir. Örneklerde TEA miktarının belirlenmesi amacıyla $2 \mathrm{ml}$ meyve suyu, $0.1 \mathrm{~N} \mathrm{NaOH}$ çözeltisi ile pH metrede (Inolab pH 720, WTW, Germany) $\mathrm{pH}=8.1$ 'e kadar titre edilmiştir. Sonuçlar \% sitrik asit cinsinden hesaplanmıştır. Meyvelerin renk ölçümleri Meyvelerin kabuk renginde meydana gelen değişmeler meyvenin ekvator bölgesinden üç farklı noktadan Minolta CR400 (MINOLTA Camera Co, LTD Ramsey, NJ) marka renk ölçer ile CIE L*a*b* renk düzleminde belirlenmiştir (McGuire 1992). Çalışmada meyve eti sertliği el penetromesi yardımıyla meyve ekvator bölgesinden üç farklı noktadan ölçülmüştür. Ölçümler 3mm'lik bir çapa sahip uçla gerçekleştirilmiştir.

Denemede meyve ucu çürüklüğüne (BER) sahip meyveler sayılmış ve ağırlığ $(\mathrm{g})$ tartılarak belirlenmiştir.

Elde edilen veriler SPSS 17.0 paket programında varyans analizi yapılarak Duncan çoklu karşılaştırma testine tabi tutulmuştur.

\section{Bulgular ve Tartışma}

Farklı dozlarda tavuk gübresi ve EC uygulamalarının deneme toprağının bazı fiziksel ve kimyasal özellikleri ile toprağın makro besin elementi üzerine olan etkileri Çizelge 3 'de verilmiştir.

Uygulamaların toprak pH değeri üzerine etkileri istatistiksel olarak önemsiz bulunmuştur. En yüksek pH değeri 7.43 ve en düşük $\mathrm{pH}$ değeri 7.42 olarak belirlenmiştir. Araştırma konularının toprak kireç kapsamı üzerine etkileri istatistiksel olarak önemsiz bulunmuştur. En yüksek kireç içeriği (\%19.52) TG0 $\mathrm{kg} \mathrm{da}^{-1}+\mathrm{FRT} \mathrm{EC}_{1.5}$ uygulamasından elde edilirken, en düşük kireç içeriği $(\% 16.77) \quad \mathrm{TG}_{2} \quad \mathrm{~kg} \mathrm{da}^{-1}+\mathrm{FRT}^{2} \mathrm{EC}_{3}$ uygulamasından elde edilmiştir. Dikinya ve Mufwanzala (2010) tarafından TG uygulamalarının toprak $\mathrm{pH}^{\prime}$ 'sını değiştirmediğini belirtilmiştir.

Uygulamaların toprak tuzluluğu üzerine etkileri incelendiğinde tavuk gübresi $(\mathrm{p}<0.001)$ ve fertigasyon EC değeri $(p<0.001)$ istatisitiksel olarak önemli bulunurken, TG*FRT.EC önemsiz bulunmuştur. En yüksek toprak EC değeri, TG800 $\mathrm{kg} \mathrm{da}^{-1}+\mathrm{FRT} \mathrm{EC}_{3}$ uygulamasından elde edilirken en düşük toprak EC değeri TG $\mathrm{kg} \mathrm{da}^{-1}+\mathrm{FRT}_{0} \mathrm{EC}_{1.5}$ uygulamasından elde edilmiştir. Tavuk gübresi uygulamalarının toprak tuzluluğu artırdığına yönelik çalışmaları mevcuttur (Korkmaz ve ark. 1996, Tavalı ve ark. 2014; Kaplan ve Maltaş 2016). 500, 1000 ve 2000 mhos $\mathrm{cm}^{-1}$ EC'ye sahip sulama suları ile sulama yapılmasının toprak tuzluluğunu sezon sonunda arttırdığını bildirmiştir (Kadiroğlu ve Kaplan 2000).

Toprağa artan düzeylerde uygulanan tavuk gübresinin, toprak O.M miktarı üzerine $\mathrm{P}<0.001$ düzeyinde önemli olduğu, fertigasyon EC dozlarının ve TG x FRT.EC interaksiyonunun toprak O.M'si üzerine istatistiksel olarak önemsiz olduğu tespit edilmiştir. En yüksek organik madde içeriği (\%3.15) TG800 $\mathrm{kg} \mathrm{da}^{-1}+\mathrm{FRT} \mathrm{EC}_{3}$, en düşük organik madde içeriği ise $\mathrm{TG}_{0}$ $\mathrm{kg} \mathrm{da}^{-1}+$ FRT.EC $_{1.5}$ uygulamasında tespit edilmiştir. Tavuk gübresi uygulamalarının toprak organik maddesini artırdığ bilinmektedir (Şahin ve Altunay 2008, Yılmaz ve Alagöz 2010, Sönmez ve ark. 2019).

Çizelge 3. Uygulamaların toprağın bazı fiziksel ve kimyasal özellikleri ile makro besin konsantrasyonları üzerine etkileri.

Table 3. Effects of applications on some physical and chemical properties of soil and macronutrient concentrations.

\begin{tabular}{|c|c|c|c|c|c|c|c|c|c|c|c|}
\hline \multicolumn{2}{|c|}{ Uygulama Konuları } & \multicolumn{4}{|c|}{ Fiziksel ve kimyasal özellikler } & \multicolumn{6}{|c|}{ Toprak Makro Besin Elementleri } \\
\hline $\begin{array}{l}\text { Tavuk } \\
\text { Gübresi } \\
\left(\mathrm{kg} \mathrm{da}^{-1}\right) \\
\end{array}$ & Gübreleme & $\mathrm{pH}$ & $\begin{array}{c}\mathrm{CaCO}_{3} \\
(\%)\end{array}$ & 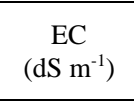 & $\begin{array}{l}\text { O.M. } \\
(\%)\end{array}$ & $\begin{array}{l}\mathrm{N} \\
(\%)\end{array}$ & $\begin{array}{c}\mathrm{P} \\
(\mathrm{ppm})\end{array}$ & $\begin{array}{c}\mathrm{K} \\
\left(\mathrm{me} 100 \mathrm{~g}^{-1} \text { ) }\right.\end{array}$ & $\begin{array}{c}\mathrm{Ca} \\
\left(\mathrm{me} 100 \mathrm{~g}^{-1}\right)\end{array}$ & $\begin{array}{c}\mathrm{Mg} \\
\text { (me } 100 \mathrm{~g}^{-1} \text { ) }\end{array}$ & $\begin{array}{c}\mathrm{Na} \\
\left(\mathrm{me} 100 \mathrm{~g}^{-1}\right)\end{array}$ \\
\hline \multirow{2}{*}{$\mathrm{TG}_{0}$} & $\mathrm{EC}_{1.5}$ & 7.43 & 19.52 & 0.36 & 2.69 & 0.19 & 180 & 074 & 33.96 & 4.91 & 0.23 \\
\hline & $\mathrm{EC}_{3}$ & 7.42 & 18.07 & 0.51 & 2.72 & 0.21 & 202 & 1.36 & 31.54 & 5.04 & 0.20 \\
\hline \multirow{2}{*}{$\mathrm{TG}_{1}$} & $\mathrm{EC}_{1.5}$ & 7.42 & 17.80 & 0.36 & 2.92 & 0.20 & 184 & 0.76 & 32.73 & 5.17 & 0.23 \\
\hline & $\mathrm{EC}_{3}$ & 7.43 & 17.59 & 0.50 & 2.90 & 0.22 & 180 & 1.22 & 33.73 & 5.38 & 0.25 \\
\hline \multirow{2}{*}{$\mathrm{TG}_{2}$} & $\mathrm{EC}_{1.5}$ & 7.43 & 17.69 & 0.42 & 3.12 & 0.23 & 174 & 1.10 & 32.18 & 5.12 & 0.19 \\
\hline & $\mathrm{EC}_{3}$ & 7.43 & 16.77 & 0.63 & 3.15 & 0.28 & 195 & 1.46 & 30.95 & 5.01 & 0.20 \\
\hline \multicolumn{2}{|c|}{$\begin{array}{l}\text { Önemlilik Derecesi } \\
\text { (TG X FRT.EC) }\end{array}$} & Ö.D. & Ö.D. & Ö.D. & Ö.D. & Ö.D. & Ö.D. & Ö.D. & Ö.D. & Ö.D. & Ö.D \\
\hline \multirow{3}{*}{ Ortalama } & $\mathrm{TG}_{0}$ & 7.43 & 18.80 & $0.44 b$ & $2.70 \mathrm{c}$ & $0.19 \mathrm{~b}$ & 191 & 1.05 & 32.75 & 4.97 & 0.22 \\
\hline & $\mathrm{TG}_{400}$ & 7.42 & 17.70 & $0.43 b$ & $2.91 \mathrm{~b}$ & $0.21 b$ & 182 & 0.99 & 33.23 & 5.28 & 0.24 \\
\hline & $\mathrm{TG}_{800}$ & 7.43 & 17.23 & $0.52 \mathrm{a}$ & $3.13 \mathrm{a}$ & $0.25 \mathrm{a}$ & 185 & 1.28 & 31.56 & 5.06 & 0.20 \\
\hline \multicolumn{2}{|c|}{$\begin{array}{l}\text { Önemlilik Derecesi } \\
\text { (TG) }\end{array}$} & Ö.D. & Ö.D. & $9.488 * *$ & $21.446^{* * * *}$ & $2.028 * * *$ & Ö.D. & Ö.D. & Ö.D. & Ö.D. & Ö.D. \\
\hline \multirow{2}{*}{ Ortalama } & $\mathrm{EC}_{1.5}$ & 7.43 & 18.34 & 0.38 & 2.91 & 0.21 & 179 & 0.86 & 32.96 & 5.07 & 0.22 \\
\hline & $\mathrm{EC}_{3}$ & 7.43 & 17.48 & 0.55 & 2.92 & 0.24 & 192 & 1.35 & 32.79 & 5.27 & 0.22 \\
\hline \multicolumn{2}{|c|}{$\begin{array}{l}\text { Önemlilik Derecesi } \\
\text { (FRT.EC) }\end{array}$} & Ö.D. & Ö.D. & $65.635 * * *$ & Ö.D. & $18.778^{* *}$ & Ö.D. & $12.145^{* * *}$ & Ö.D. & Ö.D. & Ö.D. \\
\hline
\end{tabular}


Uygulamaların toprağın toplam $\mathrm{N}$ konsantrasyonu üzerine etkileri değerlendirildiğinde tavuk gübresi dozlarının, $(p<0.001)$ ve fertigasyon EC dozlarının ( $\mathrm{p}<0.01)$ istatistiksel olarak önemli olduğu belirlenmiş iken; TG x FRT.EC interaksiyonu toprak toplam $\mathrm{N}$ konsantrasyonu üzerine önemsiz bulunmuştur. En yüksek toplam azot kapsam1 TG $_{800} \quad \mathrm{~kg} \mathrm{da}^{-1}+\mathrm{FRT} \mathrm{EC}_{3}$ uygulamasından elde edilirken en düşük toplam azot içeriği TG0 $\mathrm{kg} \mathrm{da}^{-1}+$ FRT.EC $_{1.5}$ uygulamasından elde edilmiştir. Alagöz ve ark. (2006) tarafindan yapılan bir çalışmada, işlenmiş tavuk gübresinin tüm dozları toprağın toplam azot içeriğini arttırmıştır.

Uygulamaların toprakta alınabilir P içeriği üzerine etkileri incelendiğinde bütün uygulamaların istatistiksel olarak önemsiz olduğu belirlenmiştir. En yüksek alınabilir P kapsamı TG $\mathrm{kg} \mathrm{da}^{-1}+\mathrm{FRT} \mathrm{EC}_{3}$, en düşük alınabilir P kapsamı ise $\mathrm{TG}_{800}$ $\mathrm{kg} \mathrm{da}^{-1}+$ FRT.EC $_{1.5}$ uygulamasından elde edilmiştir. Uygulamaların toprakta değişebilir $\mathrm{K}$ içeriği üzerine etkileri incelendiğinde fertigasyon EC dozlarının istatistiksel olarak $(\mathrm{p}<0.01)$ önemli olduğu, tavuk gübresi uygulamaları ve TG $\mathrm{x}$ FRT.EC interaksiyonu etkisinin ise istatistiksel olarak önemsiz olduğu belirlenmiştir. Çalışmadan en yüksek değişebilir $\mathrm{K}$ içeriği TG800 $\mathrm{kg} \mathrm{da}^{-1}+\mathrm{FRT} \mathrm{EC}_{3}$ uygulamasında, en düşük değişebilir $\mathrm{K}$ içeriği ise $\mathrm{TG}_{400} \quad \mathrm{~kg} \mathrm{da}^{-1}+\mathrm{FRT}$ EC $_{1.5}$ uygulamasından elde edilmiştir. Fertigasyon EC dozu arttıkça toprak değişebilir $\mathrm{K}$ konsantrasyonuda önemli düzeyde artış göstermiştir (Çizelge 1). TG x FRT.EC interaksiyonları bitkide sadece yaprak $\mathrm{K}$ konsantrasyonu üzerine istatistiksel olarak $\mathrm{p}<0.05$ düzeyinde önemli olup, en yüksek $\mathrm{K}$ konsantrasyonu TG $800 \mathrm{~kg} \mathrm{da}^{-1}+$ FRT.EC $_{1.5}$ uygulamasında görülmüştür (Çizelge 3). Toprakların değişebilir $\mathrm{Ca}, \mathrm{Mg}$ ve $\mathrm{Na}$ içerikleri üzerine uygulamaların etkileri istatistiksel olarak önemsiz bulunmuştur. Tavuk gübresi uygulamalarının toprakların değişebilir potasyum kapsamını artırdığı bilinmektedir (Sönmez ve ark. 2019). Ewulo ve Sanni (2015), tarafından tavuk gübresi kullanılarak yürütülen bir çalışmada toprakların değişebilir $\mathrm{Ca}, \mathrm{Mg}$ ve $\mathrm{Na}$ düzeyinde istatistiksel açıdan farklılı̆̆ın olmadığı tespit edilmiştir.

Uygulamaların topraklardaki alınabilir mikro element kapsamı üzerine etkileri incelendiğinde, alınabilir $\mathrm{Zn}$ ve $\mathrm{B}$ bakımından istatistiksel farklılığın olduğu görülürken alınabilir $\mathrm{Fe}, \mathrm{Mn}$ ve $\mathrm{Cu}$ bakımdan istatistiksel bir farklılık belirlenmemiştir (Çizelge 4). En yüksek alınabilir $\mathrm{Zn}$ ve B içeriği TG400 $\mathrm{kg} \mathrm{da}^{-1}+\mathrm{FRT} \mathrm{EC}_{1.5}$ uygulamasından elde edilmiştir (Çizelge 2). Kara ve Erel (1999), yulaf bitkisi üzerine yaptıkları çalışmada artan tavuk gübresi dozlarına bağlı olarak, toprakta alınabilir $\mathrm{Zn}$ içeriğinin arttığını bulmuşlardır.

Farklı düzeyde uygulanan tavuk gübresi ve fertigasyon EC'lerinin domates bitkisinin yapraklarının beslenme durumları üzerine etkileri incelendiğinde $\mathrm{K}$ ve $\mathrm{Fe}$ bakımından istatistiksel farklılık olduğu, N, P, Ca, Mg, Mn, $\mathrm{Zn}, \mathrm{Cu}$ ve B bakımından istatistiksel olarak farklılığın olmadığı belirlenmiştir (Çizelge 5). Yapraklardaki en yüksek $\mathrm{K}$ içeriği TG800 $\mathrm{kg} \mathrm{da}^{-1}+$ FRT.EC 1.5 uygulamasından, en yüksek $\mathrm{Fe}$ içeriği ise $\mathrm{TG}_{0} \mathrm{~kg} \mathrm{da}^{-1}$ +FRT.EC 3.0 $_{3}$ uygulamasından elde edilmiştir. Adekiya ve Agbede (2009), tarafından yapılan bir çalışmada kimyasal gübre ve tavuk gübresi uygulamalarının domates bitkisi yapraklarının potasyum içeriğini artırdığı bildirilmiştir.

Domates meyvelerinin bitki besin elementi konsantrasyonu üzerine uygulamaların etkileri değerlendirildiğinde tavuk gübresinin meyve $\mathrm{N}$ içeriği üzerine etkisi $(\mathrm{p}<0.05)$ istatistiksel olarak önemlidir (Çizelge 6). Uygulamaların etkilerini meyvelerin $\mathrm{Mg}$ beslenmesi üzerine etkileri bakımından değerlendirildiğinde tavuk gübresi uygulamaları $(\mathrm{p}<0.001) \mathrm{EC}$ uygulamaları $(p<0.05$ ve TG x FRT.EC interaksiyonu $(p<0.01)$ istatistiksel farklılık olduğu, $\mathrm{P}, \mathrm{K}, \mathrm{Ca}, \mathrm{Fe}, \mathrm{Mn}, \mathrm{Zn}, \mathrm{Cu}$ ve $\mathrm{B}$ bakımından istatistiksel olarak farklılığın olmadığı belirlenmiştir. (Çizelge 6). Tavuk gübresi uygulamalarının, meyve eti sertliği üzerine $\mathrm{p}<0.01$ düzeyinde istatistiksel olarak önemli olduğu belirlenmiştir. En yüksek meyve eti sertliği $\mathrm{TG}_{800} \mathrm{~kg} \mathrm{da}^{-1}+\mathrm{FRT} \mathrm{EC}_{3.0}$, en düşük meyve eti sertliği ise $\mathrm{TG}_{0}$ $\mathrm{kg} \mathrm{da}^{-1}+\mathrm{FRT}$ EC $_{3.0}$ uygulamasından elde edilmiştir. Araştırma konularının diğer domates meyve kalite kriterleri olan meyve rengi $\left(\mathrm{L}^{*}, \mathrm{C}^{*}, \mathrm{~h}\right) \mathrm{SÇKM}$, meyve $\mathrm{pH}$ 'sı, meyve asitliği üzerine etkileri istatistiksel olarak önemsiz bulunmuştur (Çizelge 7). Farklı düzeyde uygulanan tavuk gübresi ve fertigasyon EC'lerinin 1. domates meyvesi üzerine etkileri incelendiğinde ortalama meyve sayısı $(\mathrm{p}<0.001)$ ve ortalama bitki başına verim $(\mathrm{p}<0.01)$ üzerine TGxFRT.EC interaksiyonu önemli bulunmuş iken, ortalama meyve çapı üzerine etkileri istatistiksel olarak önemsiz bulunmuştur. En yüksek ortalama meyve sayısı TG800 $\mathrm{kg} \mathrm{da}^{-1}+$ FRT.EC $_{3.0}$ uygulamasından en düşük ortalama meyve

Çizelge 4. Uygulamaların toprak mikro besin konsantrasyonları üzerine etkileri.

Table 4. Effects of applications on soil micronutrient concentrations.

\begin{tabular}{|c|c|c|c|c|c|c|}
\hline \multicolumn{2}{|c|}{ Uygulama Konuları } & \multicolumn{5}{|c|}{ Toprak Mikro Besin Elementleri (ppm) } \\
\hline Tavuk Gübresi $\left(\mathrm{kg} \mathrm{da}^{-1}\right)$ & Gübreleme & $\mathrm{Fe}$ & $\mathrm{Zn}$ & $\mathrm{Mn}$ & $\mathrm{Cu}$ & Bor \\
\hline \multirow{2}{*}{$\mathrm{TG}_{0}$} & $\mathrm{EC}_{1.5}$ & 5.11 & 7.57 & 11.64 & 10.19 & 0.30 \\
\hline & $\mathrm{EC}_{3}$ & 4.29 & 7.23 & 9.07 & 10.11 & 0.30 \\
\hline \multirow{2}{*}{$\mathrm{TG}_{1}$} & $\mathrm{EC}_{1.5}$ & 5.33 & 8.25 & 9.20 & 9.67 & 0.30 \\
\hline & $\mathrm{EC}_{3}$ & 5.58 & 7.69 & 11.54 & 9.85 & 0.35 \\
\hline \multirow{2}{*}{$\mathrm{TG}_{2}$} & $\mathrm{EC}_{1.5}$ & 4.78 & 8.82 & 10.50 & 9.32 & 0.37 \\
\hline & $\mathrm{EC}_{3}$ & 5.78 & 8.32 & 12.69 & 9.82 & 0.40 \\
\hline \multicolumn{2}{|c|}{ Önemlilik Derecesi (TG X FRT.EC) } & Ö.D. & Ö.D. & Ö.D. & Ö.D. & Ö.D. \\
\hline \multirow{3}{*}{ Ortalama } & $\mathrm{TG}_{0}$ & 4.70 & $7.40 \mathrm{~b}$ & 10.35 & 10.15 & $0.30 \mathrm{~b}$ \\
\hline & $\mathrm{TG}_{400}$ & 5.45 & $7.97 \mathrm{ab}$ & 10.37 & 9.76 & $0.32 b$ \\
\hline & $\mathrm{TG}_{800}$ & 5.28 & $8.57 \mathrm{a}$ & 11.60 & 9.57 & $0.39 \mathrm{a}$ \\
\hline \multicolumn{2}{|l|}{ Önemlilik Derecesi (TG) } & Ö.D. & $3.178 *$ & Ö.D. & Ö.D. & $6,124 *$ \\
\hline \multirow{2}{*}{ Ortalama } & $\mathrm{EC}_{1.5}$ & 5.07 & 8.21 & 10.45 & 9.72 & 0.33 \\
\hline & $\mathrm{EC}_{3}$ & 4.82 & 7.88 & 11.97 & 9.88 & 0.34 \\
\hline \multicolumn{2}{|c|}{ Önemlilik Derecesi (FRT.EC) } & Ö.D. & Ö.D. & Ö.D. & Ö.D. & Ö.D. \\
\hline
\end{tabular}


Çizelge 5. Uygulamaların yaprak besin konsantrasyonları üzerine etkileri.

Table 5. Effects of applications on leaf nutrient concentrations.

\begin{tabular}{|c|c|c|c|c|c|c|c|c|c|c|c|}
\hline \multicolumn{2}{|c|}{ Uygulama Konuları } & \multicolumn{5}{|c|}{ Yaprak Besin Elementleri (\%) } & \multicolumn{5}{|c|}{ Yaprak Besin Elementleri (ppm) } \\
\hline Tavuk Gübresi $\left(\mathrm{kg} \mathrm{da}^{-1}\right)$ & Gübreleme & $\mathrm{N}$ & $\mathrm{P}$ & $\mathrm{K}$ & $\mathrm{Ca}$ & $\mathrm{Mg}$ & $\mathrm{Fe}$ & $\mathrm{Mn}$ & $\mathrm{Zn}$ & $\mathrm{Cu}$ & Bor \\
\hline \multirow{2}{*}{$\mathrm{TG}_{0}$} & $\mathrm{EC}_{1.5}$ & 2.18 & 0.47 & $1.75 \mathrm{c}$ & 6.32 & 1.00 & 105.38 & 119.66 & 26.41 & 6.55 & 43.73 \\
\hline & $\mathrm{EC}_{3}$ & 2.42 & 0.56 & $1.95 \mathrm{ab}$ & 6.15 & 1.08 & 135.77 & 138.81 & 35.25 & 8.52 & 48.04 \\
\hline \multirow{2}{*}{$\mathrm{TG}_{400}$} & $\mathrm{EC}_{1.5}$ & 2.33 & 0.46 & $1.80 \mathrm{bc}$ & 6.26 & 1.01 & 109.02 & 120.39 & 25.76 & 6.27 & 45.12 \\
\hline & $\mathrm{EC}_{3}$ & 2.54 & 0.41 & $1.85 \mathrm{~b}$ & 6.51 & 0.99 & 133.24 & 129.89 & 27.38 & 5.51 & 44.56 \\
\hline \multirow{2}{*}{$\mathrm{TG}_{800}$} & $\mathrm{EC}_{1.5}$ & 2.34 & 0.44 & $2.09 \mathrm{a}$ & 6.45 & 1.10 & 105.18 & 144.13 & 25.05 & 5.36 & 43.27 \\
\hline & $\mathrm{EC}_{3}$ & 2.51 & 0.47 & $1.73 \mathrm{c}$ & 6.20 & 0.94 & 132.36 & 131.36 & 21.98 & 6.72 & 42.55 \\
\hline \multicolumn{2}{|c|}{ Önemlilik Derecesi (TG X FRT.EC) } & Ö.D & Ö.D & $6,487^{*}$ & Ö.D & Ö.D & Ö.D & Ö.D & Ö.D & Ö.D & Ö.D \\
\hline \multirow{3}{*}{ Ortalama } & $\mathrm{TG}_{0}$ & 2.30 & 0.52 & 1.85 & 6.24 & 1.04 & 120.58 & 129.24 & 30.83 & 7.54 & 45.89 \\
\hline & $\mathrm{TG}_{400}$ & 2.44 & 0.44 & 1.83 & 6.39 & 1.00 & 121.13 & 125.14 & 26.57 & 5.89 & 44.84 \\
\hline & $\mathrm{TG}_{800}$ & 2.43 & 0.46 & 1.91 & 6.33 & 1.02 & 118.77 & 137.75 & 23.52 & 6.04 & 42.91 \\
\hline \multicolumn{2}{|c|}{ Önemlilik Derecesi (TG) } & Ö.D & Ö.D & Ö.D & Ö.D & Ö.D & Ö.D & Ö.D & Ö.D & Ö.D & Ö.D \\
\hline \multirow{2}{*}{ Ortalama } & $\mathrm{EC}_{1.5}$ & 2.28 & 0.46 & 1.88 & 6.34 & 1.04 & $106.53 b$ & 128.06 & 25.74 & 6.06 & 44.04 \\
\hline & $\mathrm{EC}_{3}$ & 2.49 & 0.48 & 1.84 & 6.29 & 1.00 & $133.79 \mathrm{a}$ & 133.35 & 28.20 & 6.92 & 45.05 \\
\hline \multicolumn{2}{|c|}{ Önemlilik Derecesi (FRT.EC) } & Ö.D & Ö.D & Ö.D & Ö.D & Ö.D & $10.910 *$ & Ö.D & Ö.D. & Ö.D. & Ö.D. \\
\hline
\end{tabular}

Çizelge 6. Uygulamaların 1. kalite meyve besin konsantrasyonları üzerine etkileri.

Table 6. Effects of applications on $1^{\text {st }}$ quality fruit nutrient concentrations.

\begin{tabular}{|c|c|c|c|c|c|c|c|c|c|c|c|}
\hline \multicolumn{2}{|c|}{ Uygulama Konuları } & \multicolumn{5}{|c|}{ Meyve Makro Besin Elementleri (\%) } & \multicolumn{5}{|c|}{ Meyve Mikro Besin Elementleri (ppm) } \\
\hline Tavuk Gübresi $\left(\mathrm{kg} \mathrm{da}^{-1}\right)$ & Gübreleme & $\mathrm{N}$ & $\mathrm{P}$ & $\mathrm{K}$ & $\mathrm{Ca}$ & $\mathrm{Mg}$ & $\mathrm{Fe}$ & $\mathrm{Mn}$ & $\mathrm{Zn}$ & $\mathrm{Cu}$ & Bor \\
\hline \multirow{2}{*}{$\mathrm{TG}_{0}$} & FRT.EC 1.5 & 1.41 & 0.12 & 2.94 & 0.08 & 0.10 & 21.38 & 6.83 & 7.81 & 13.36 & 6.79 \\
\hline & FRT.EC $_{3}$ & 1.39 & 0.13 & 2.97 & 0.08 & 0.10 & 15.76 & 7.21 & 8.16 & 12.25 & 8.01 \\
\hline \multirow{2}{*}{$\mathrm{TG}_{400}$} & FRT.EC $_{1.5}$ & 1.52 & 0.11 & 3.01 & 0.08 & 0.10 & 19.64 & 6.37 & 7.38 & 10.94 & 6.81 \\
\hline & $\mathrm{FRT}^{\mathrm{ERC}} \mathrm{E}_{3}$ & 1.58 & 0.12 & 2.93 & 0.08 & 0.08 & 13.8 & 6.96 & 8.67 & 11.31 & 8.49 \\
\hline \multirow{2}{*}{$\mathrm{TG}_{800}$} & FRT.EC $_{1.5}$ & 1.53 & 0.12 & 3.00 & 0.08 & 0.10 & 13.25 & 6.86 & 8.61 & 8,52 & 9.64 \\
\hline & $\mathrm{FRT}^{\mathrm{ERC}} \mathrm{E}_{3}$ & 1.60 & 0.12 & 2.89 & 0.08 & 0.10 & 15.33 & 6.76 & 7.76 & 9.65 & 6.66 \\
\hline \multicolumn{2}{|c|}{ Önemlilik Derecesi (TG X FRT.EC) } & Ö.D. & Ö.D & Ö.D. & Ö.D. & $5.210^{*}$ & Ö.D & Ö.D & Ö.D & Ö.D & Ö.D \\
\hline \multirow{3}{*}{ Ortalama } & $\mathrm{TG}_{0}$ & $1.40 \mathrm{~b}$ & 0.13 & 2.96 & 0.08 & $0.10 \mathrm{a}$ & 18.57 & 7.02 & 7.99 & 12.81 & 7.40 \\
\hline & $\mathrm{TG}_{400}$ & $1.55 \mathrm{a}$ & 0.12 & 2.97 & 0.08 & $0.09 \mathrm{~b}$ & 16.72 & 6.67 & 8.03 & 11.13 & 7.65 \\
\hline & $\mathrm{TG}_{800}$ & $1.57 \mathrm{a}$ & 0.12 & 2.95 & 0.08 & $0.10 \mathrm{a}$ & 14.29 & 6.81 & 8.19 & 9.09 & 8.15 \\
\hline \multicolumn{2}{|c|}{ Önemlilik Derecesi (TG) } & $5.793^{*}$ & Ö.D & Ö.D & Ö.D & $9.280 * *$ & Ö.D & Ö.D & Ö.D & Ö.D & Ö.D \\
\hline \multirow{2}{*}{ Ortalama } & $\mathrm{EC}_{1.5}$ & 1.49 & 0.12 & 2.98 & 0.08 & 0.10 & 18.09 & 6.69 & 7.93 & 10.94 & 7.75 \\
\hline & $\mathrm{EC}_{3}$ & 1.52 & 0.12 & 2.93 & 0.08 & 0.09 & 14.96 & 6.98 & 8.20 & 11.07 & 7.72 \\
\hline \multicolumn{2}{|c|}{ Önemlilik Derecesi (FRT.EC) } & Ö.D & Ö.D & Ö.D & Ö.D & $5.155^{*}$ & Ö.D & Ö.D & Ö.D & Ö.D & Ö.D \\
\hline
\end{tabular}

Çizelge 7. Uygulamaların meyve 1. kalite kriterleri üzerine etkileri.

Table 7. The effects of the applications on the fruit $1^{\text {st }}$ quality criteria.

\begin{tabular}{|c|c|c|c|c|c|c|c|c|}
\hline \multicolumn{2}{|c|}{ Uygulama Konuları } & \multicolumn{7}{|c|}{ Meyve Kalite Kriterleri } \\
\hline Tavuk Gübresi $\left(\mathrm{kg} \mathrm{da}^{-1}\right)$ & Gübreleme & $\mathrm{L}^{*}$ & $\mathrm{C}^{*}$ & $\mathrm{~h}$ & $\begin{array}{c}\text { Meyve Kuru } \\
\text { Maddesi (SÇKM \%) } \\
\end{array}$ & $\mathrm{pH}$ & $\begin{array}{l}\text { Meyve Asitliği } \\
\text { Ort. (\%) }\end{array}$ & $\begin{array}{c}\text { Meyve Eti Sertliği } \\
\left(\mathrm{kg} \mathrm{cm}^{-2}\right)\end{array}$ \\
\hline \multirow{2}{*}{$\mathrm{TG}_{0}$} & FRT.EC 1.5 & 39.71 & 39.79 & 40.35 & 5.87 & 4.50 & 0.32 & 45.00 \\
\hline & FRT.EC $_{3}$ & 39.47 & 39.71 & 39.60 & 6.27 & 4.46 & 0.34 & 44.55 \\
\hline \multirow{2}{*}{$\mathrm{TG}_{400}$} & FRT.EC $_{1.5}$ & 39.60 & 39.47 & 40.04 & 6.10 & 4.47 & 0.34 & 48.93 \\
\hline & $\mathrm{FRT}^{\mathrm{ERC}} \mathrm{E}_{3}$ & 39.98 & 40.07 & 39.49 & 6.27 & 4.47 & 0.36 & 46.55 \\
\hline \multirow{2}{*}{$\mathrm{TG}_{800}$} & FRT.EC 1.5 & 39.60 & 39.37 & 39.56 & 6.17 & 4.52 & 0.33 & 50.38 \\
\hline & $\mathrm{FRT}^{\mathrm{ERC}} \mathrm{E}_{3}$ & 39.93 & 39.58 & 40.48 & 5.70 & 4.47 & 0.33 & 53.76 \\
\hline \multicolumn{2}{|c|}{ Önemlilik Derecesi (TG X FRT.EC) } & Ö.D & Ö.D & Ö.D & Ö.D & Ö.D & Ö.D & Ö.D \\
\hline \multirow{3}{*}{ Ortalama } & $\mathrm{TG}_{0}$ & 39.59 & 39.75 & 39.98 & 6.07 & 4.48 & 0.33 & $44.78 \mathrm{~b}$ \\
\hline & $\mathrm{TG}_{400}$ & 39.79 & 39.77 & 39.77 & 6.19 & 4.47 & 0.35 & $47.74 \mathrm{~b}$ \\
\hline & $\mathrm{TG}_{800}$ & 39.77 & 39.48 & 40.02 & 5.94 & 4.50 & 0.33 & $52.07 \mathrm{a}$ \\
\hline \multicolumn{2}{|l|}{ Önemlilik Derecesi (TG) } & Ö.D & Ö.D & Ö.D & Ö.D & Ö.D & Ö.D & $10.700 * *$ \\
\hline \multirow{2}{*}{ Ortalama } & $\mathrm{EC}_{1,5}$ & 39.64 & 39.54 & 39.98 & 6.05 & 4.50 & 0.33 & 48.10 \\
\hline & $\mathrm{EC}_{3}$ & 39.79 & 39.79 & 39.86 & 6.08 & 4.47 & 0.34 & 48.29 \\
\hline \multicolumn{2}{|c|}{ Önemlilik Derecesi (FRT.EC) } & Ö.D & Ö.D & Ö.D & Ö.D & Ö.D & Ö.D & Ö.D \\
\hline
\end{tabular}


sayıs1 ise TG$_{800} \mathrm{~kg} \mathrm{da}^{-1}+\mathrm{FRT} \mathrm{EC}_{1.5}$ uygulamasından elde edilmiştir. En yüksek ortalama bitki başına verim $\mathrm{TG}_{800} \mathrm{~kg} \mathrm{da}^{-1}$ + FRT.EC 3.0 uygulamasından en düşük ortalama bitki başına verim ise $\mathrm{TG}_{400} \mathrm{~kg} \mathrm{da}^{-1}+\mathrm{FRT} \mathrm{EC}_{1.5}$ uygulamasindan elde edilmiştir. Adekiya ve Agbede (2009) tarafindan domates bitkisi üzerinde yapılan bir çalışmada tavuk gübresinin meyve verimi ve bitki başına meyve sayısını artırdığı belirlenmiştir.

Araştırma konuların domates meyvesinin 2. kalite meyve verimi ve kalitesi üzerine etkileri değerlendirildiğinde, ortalama meyve ucu çürüklüğüne (BER) sahip meyve ağırlığı üzerine TG $\mathrm{x}$ FRT.EC interaksiyonları $(\mathrm{p}<0.01)$ istatistiksel olarak önemli bulunmuştur. En yüksek BER ağırlığ $\mathrm{TG}_{400} \quad \mathrm{~kg} \mathrm{da}^{-1}+$ FRT.EC 3.0 ve en düşük BER ağırlığ $\mathrm{TG}_{0} \mathrm{~kg} \mathrm{da}^{-1}+$ FRT.EC $_{1.5}$ ve $\mathrm{TG}_{800} \mathrm{~kg} \mathrm{da}^{-1}+\mathrm{FRT}$ EC $_{3.0}$ uygulamalarından elde edilmiştir. BER sayıs1 üzerine TG $(\mathrm{p}<0.001)$, FRT.EC $(\mathrm{p}<0.001)$ ve TG $\mathrm{x}$ FRT.EC interaksiyonları $(\mathrm{p}<0.001)$ istatistiksel olarak önemli bulunmuştur. En yüksek BER sayıs1 $\mathrm{TG}_{400} \mathrm{~kg} \mathrm{da}^{-1}+\mathrm{FRT}^{-E_{3.0}}$ ve en düşük BER sayısı TG $\mathrm{kg} \mathrm{da}^{-1}+\mathrm{FRT}_{0} \mathrm{EC}_{1.5}$ uygulamasından elde edilmiştir. Uygulamaların 2. kalite domates meyvesinin ortalama meyve çapı, ortalama meyve ağırlığ üzerine etkileri istatistiksel olarak önemsiz bulunmuştur (Çizelge 8).

\section{Sonuç ve Öneriler}

Organik materyallerin toprakların fiziksel, kimyasal ve biyolojik özelliklerini iyileştirerek, bitkisel üretimde verim ve kaliteyi olumlu etkilediği bilinmektedir. Ancak ülkemiz topraklarının organik madde genel itibari ile düşüktür. Tarım modellerinin değişimi ile düşük olan organik madde kapsamının, zamanla daha da düşebileceği öngörülebilir. Tarım modellerinin değişimi, toprak işleme ile birleştiğinde toprak organik maddesinin her geçen gün daha hızlı bir şekilde azalabileceği düşünülmektedir.
Toprak organik madde düzeyinin azlığına bağlı olarak, ülkemizdeki her türlü organik materyalin varsa riskleri giderildikten sonra bitkisel üretimde kullanılmasının çok yönlü faydaları olduğu düşünülmektedir. $\mathrm{Bu}$ amaçla yaptığımız çalışmada, uygulamaların etkileri incelenen bazı kriterler üzerine istatistiksel olarak önemli farklar oluşturmuşken, birçok kriterde de farklar istatistiksel olarak önemsiz düzeydedir.

Tavuk gübresi ve fertigasyon EC'sinin temsil ettiği konular, birçok alt faktörün (besin içerikleri vb.) bileşimini temsil etmektedir. $\mathrm{Bu}$ bileşenlerin bazılarının etkileri incelenen özellikleri olumlu etkilerken, diğer bazıları olumsuz etkileyebileceği ya da sezon başı ve sonuna doğru aynı özelliğin etkilerinin, değişen sera iklimi nedeniyle farklı olabileceği gözden uzak tutulmamalıdır. Etkileşimlerin çoklu ve karmaşık olduğuna dikkat etmek gerekmektedir.

Birinci kalite meyve verimi ve meyve sayısı üzerine en etkili uygulamanın $\mathrm{TG}_{800} \mathrm{~kg} \mathrm{da}^{-1}+$ FRT.EC $_{3}$ olduğu belirlenmiştir. Gözlemlerimiz uygulanan tavuk gübresinin önemli bir bölümünün yeterince parçalanmadan yetiştirme ortamında kaldığını göstermiştir. Bu sebeple kullanılan tavuk gübresinin bir sonraki yetiştirme döneminde de etkinliğini sürdürme olasılığı yüksektir. Gübrenin pelet yapıda olmasının bu sonuca yol açtığını tahmin edebiliriz. Bu gübrenin kısa dönem yetiştiricilikteki etkilerinin bu fiziksel yapılarından önemli düzeyde etkilenebileceği, etkilerinin çok daha uzun sürelerde ortaya çıkabileceği öngörülmelidir. Bu özellikteki gübrelerden ilk yetiştirme sezonundan daha etkili sonuçlar alabilmek için toprak hazırlığının, dikimden belirli bir süre önce yapılmasını, organik gübre peletlerinin daha hılı parçalanıp ayrışabilmesi için sulama yapılarak bitki dikiminden önce de sürecin başlatılmasına katkı sunulması, hatta solarizasyon döneminde uygulanılabileceği, bu konuda yeni araştırmaların yapılması gerekliliğine vurgu yapabiliriz. Toprak hazırlığının önceden yapılamadığı durumlarda pelet yerine toz tavuk gübresi şeklindeki uygulamaların ve doz belirlemelerinin çalışılması daha doğru bir seçenek olarak önerilebilir.

Çizelge 8. Uygulamaların meyve verimi ve bazı meyve kalitesi üzerine etkileri.

Table 8. Effects of applications on fruit yield and some fruit quality.

\begin{tabular}{|c|c|c|c|c|c|c|c|c|c|c|c|}
\hline \multicolumn{6}{|c|}{ Uygulamaların 1. kalite hasat verileri üzerine etkileri } & \multicolumn{6}{|c|}{ Uygulamaların 2. kalite hasat verileri üzerine etkileri } \\
\hline $\begin{array}{l}\text { Tavuk } \\
\text { Gübresi } \\
\left(\mathrm{kg} \mathrm{da}^{-1}\right)\end{array}$ & Gübreleme & $\begin{array}{c}\text { Ortalama } \\
\text { Meyve Çap1 } \\
\left(\mathrm{mm} \text { meyve }^{-1}\right)\end{array}$ & $\begin{array}{c}\text { Meyve } \\
\text { Sayıs1 } \\
\text { (adet/bitki) }\end{array}$ & $\begin{array}{c}\text { Meyve } \\
\text { Verimi } \\
\left(\mathrm{kg} \mathrm{bitki}^{-1}\right)\end{array}$ & $\begin{array}{c}\text { Ortalama } \\
\text { Meyve } \\
\text { Ağırlığ1 } \\
\left(\mathrm{g} \text { meyve }{ }^{-1}\right) \\
\end{array}$ & $\begin{array}{c}\text { Ortalama } \\
\text { Meyve Çapı } \\
\left(\mathrm{mm} \text { meyve }^{-1}\right)\end{array}$ & $\begin{array}{c}\text { Meyve } \\
\text { Sayısı } \\
\text { (adet/bitki) }\end{array}$ & $\begin{array}{c}\text { Meyve } \\
\text { Verimi } \\
\left(\mathrm{kg} \mathrm{bitki}^{-1}\right)\end{array}$ & $\begin{array}{c}\text { Ortalama } \\
\text { Meyve } \\
\text { Ağırlığı } \\
\left(\mathrm{g} \mathrm{meyve}^{-1}\right) \\
\end{array}$ & $\begin{array}{c}\text { BER } \\
\text { Ağırlığı } \\
\left(\mathrm{kg} \mathrm{bitki}^{-1}\right)\end{array}$ & $\begin{array}{c}\text { BER } \\
\text { Say1s1 } \\
\text { (adet/bitki) }\end{array}$ \\
\hline \multirow{2}{*}{$\mathrm{TG}_{0}$} & FRT.EC $_{1,5}$ & 70.22 & $17.88 \mathrm{~b}$ & $2.56 \mathrm{~b}$ & 143.09 & 51.48 & 5.06 & 0.46 & 90.41 & $0.51 \mathrm{c}$ & $5.74 \mathrm{~d}$ \\
\hline & FRT.EC $_{3}$ & 68.28 & $14.47 \mathrm{bc}$ & $2.00 \mathrm{c}$ & 138.21 & 50.08 & 7.53 & 0.69 & 92.03 & $0.65 \mathrm{~b}$ & $7.44 \mathrm{~b}$ \\
\hline \multirow{2}{*}{$\mathrm{TG}_{400}$} & FRT.EC $_{1,5}$ & 70.14 & $18.06 \mathrm{~b}$ & $2.53 \mathrm{~b}$ & 140.07 & 51.31 & 5.44 & 0.49 & 90.16 & $0.53 \mathrm{c}$ & $6.29 \mathrm{c}$ \\
\hline & FRT.EC $_{3}$ & 66.51 & $13.74 \mathrm{c}$ & $1.82 \mathrm{~d}$ & 132.76 & 49.68 & 7.12 & 0.60 & 84.83 & $0.75 \mathrm{a}$ & $10.03 \mathrm{a}$ \\
\hline \multirow{2}{*}{$\mathrm{TG}_{800}$} & FRT.EC $_{1,5}$ & 68.28 & $13.56 \mathrm{c}$ & $1.91 \mathrm{dc}$ & 141.00 & 51.20 & 6.94 & 0.67 & 95.81 & $0.66 \mathrm{~b}$ & $7.68 \mathrm{~b}$ \\
\hline & FRT.EC $_{3}$ & 69.91 & $19.59 \mathrm{a}$ & $2.76 \mathrm{a}$ & 141.14 & 51.13 & 5.82 & 0.52 & 89.95 & $0.51 \mathrm{c}$ & $5.97 \mathrm{~cd}$ \\
\hline \multicolumn{2}{|c|}{$\begin{array}{l}\text { Önemlilik Derecesi } \\
\text { (TG x FRT.EC) }\end{array}$} & Ö.D & $16.505^{* * *}$ & $12.601 * *$ & Ö.D & Ö.D & Ö.D & Ö.D & Ö.D & $4.848^{* *} *$ & $57.039 * * *$ \\
\hline \multirow{3}{*}{ Ortalama } & $\mathrm{TG}_{0}$ & 69.25 & 16.18 & 2.28 & 140.91 & 50.78 & 6.29 & 0.58 & 91.38 & 0.58 & $6.59 b$ \\
\hline & $\mathrm{TG}_{400}$ & 68.00 & 15.90 & 2.18 & 136.91 & 50.50 & 6.28 & 0.55 & 87.14 & 0.64 & $8.16 \mathrm{a}$ \\
\hline & $\mathrm{TG}_{800}$ & 69.10 & 16.57 & 2.32 & 140.20 & 51.17 & 6.38 & 0.59 & 93.13 & 0.59 & $6.82 b$ \\
\hline \multicolumn{2}{|c|}{$\begin{array}{l}\text { Önemlilik Derecesi } \\
\text { (TG) }\end{array}$} & Ö.D & Ö.D & Ö.D & Ö.D & Ö.D & Ö.D & Ö.D & Ö.D & Ö.D & $21.638^{* * * *}$ \\
\hline \multirow{2}{*}{ Ortalama } & FRT.EC $_{1,5}$ & 69.55 & 16.50 & 2.33 & 141.41 & 51.33 & 5.81 & 0.54 & 92.48 & 0.56 & 6.57 \\
\hline & FRT.EC $_{3}$ & 68.23 & 15.93 & 2.20 & 137.85 & 50.30 & 6.82 & 0.61 & 88.94 & 0.64 & 7.81 \\
\hline \multicolumn{2}{|c|}{$\begin{array}{l}\text { Önemlilik Derecesi } \\
\text { (EC) }\end{array}$} & Ö.D & Ö.D & Ö.D & Ö.D & Ö.D & Ö.D & Ö.D & Ö.D & Ö.D. & $34.788 * * *$ \\
\hline
\end{tabular}




\section{Teşekkür}

$\mathrm{Bu}$ çalışma Akdeniz Üniversitesi Bilimsel Araştırma Projeleri Birimi'nin FYL-2016-1237 numaralı Yüksek Lisans Tez projesi kapsamında desteklenmiştir.

\section{Kaynaklar}

Adekiya AO, Agbede TM (2009) Growth and yield of tomato as influenced by poultry manure and NPK fertilizer. Emirates Journal of Food and Agriculture 21(1): 10-20.

Alagöz Z, Yılmaz E, Öktüren F (2006) Organik materyal ilavesinin bazı fiziksel ve kimyasal toprak özellikleri üzerine etkileri. Akdeniz Üniversitesi Ziraat Fakültesi Dergisi 19(2): 245-254.

Black CA (1957) Soil-plant relationships. John Wiley and Sons, Inc., Newyork,

Black CA (1965) Methods of soil analysis Part 2. Amer. Society of Agronomy Inc., Publisher Madisson, Wilconsin.

Bouyoucos GJ (1955) A recalibration of the hydrometer method for making mechanical analysis of the soils. Agronomy Journal 4(9): 434.

Bower CA, Wilcox LL (1965) Soluble salt methods of soil analysis, Methods of soil analysis Part 2, Am. Soc. Agron., No: 9, Madison, pp: 933-940.

Demirtaş EI, Öktüren Asri F, Özkan FC, Arı N (2012) Organik ve kimyasal gübre uygulamalarının örtüaltı domates yetiştiriciliğinde toprak verimliliği ve bitkinin beslenmesine etkileri. Derim Dergisi 29(1): 9-22.

Dikinya O, Mufvanzala N (2010) Chicken manure-enhanced soil fertility and productivity: Effects of application rates. Journal of Soil Science and Environmental Management 1: 46-54.

Dinç U, Şenol S, Kapur S, Cangir C, Atalay İ (2001) Türkiye Toprakları, Çukurova Üniversitesi, Ziraat Fakültesi Genel Yayın No: 51, Ders Kitab1, Adana.

Evliya H (1964) Kültür bitkilerinin beslenmesi. Ankara Üniversitesi Ziraat Fakültesi Yayınları 36: 292-294.

Ewulo BS, Sanni KO (2015) Effects of poultry manure, NPK 15-15-15 fertilizer and their combination on vegetative growth and yield parameter of tomato (Lycopersicon esculentum var. mill.). New York Science Journal 8(4): 70-75.

FAO (2018) Food and Agriculture Organization of the United Nations (FAO). FAOSTAT, http://www. fao.org/faostat/en/\#data/QC.

Güvenç İ (2019). Türkiye'de domates üretimi, dış ticareti ve rekabet gücü. Tarim ve Doga Dergisi 22(1): 57.

Jackson MC (1967). Soil chemical analysis. Prentice Hall of India Private'Limited, New Delhi, pp. 498.

Kacar B (1972) Bitki ve Toprağın Kimyasal Analizleri II. Bitki Analizleri Ankara Üniversitesi Ziraat Fak. Yayınları: 453, Ders Kitab1, Ankara.
Kacar B, İnal A (2008) Bitki analizleri. Nobel Yayınları: 1241, Ders Kitabı, Ankara.

Kadiroğlu A, Kaplan M (2000) Değişik düzeylerdeki su tuzluluğu ve gübrelemelerin tek ürün hıyar yetiştiriciliğinde bitki gelişmesi ve verim üzerine etkileri. Anadolu Ege Tarımsal Araştırma Enstitüsü Dergisi 10(2): 126-138.

Kalkan H, Gözükara G, Kaplan M (2017) Sera güzlük domates yetiştiriciliğinde yeni eğilim: sıvı organik gübre tüketimi. Academia Journal of Engineering and Applied Sciences 2(3): 92-100.

Kaplan M, Maltaş AŞ (2016) Tavuk Atıklarının Gübre Olarak Kullanılmasında Zorluklar ve Firsatlar. 3. International Poultry Meat Congress, Antalya, s. 176-181.

Kara E, Erel A (1999) Tavuk gübresinin bazı toprak özelliklerine ve yulaf kuru bitki ağırlığına etkisi. Anadolu Ege Tarımsal Araştırma Enstitüsü Dergisi 9 (2), 91-104.

Korkmaz A, Sürücü A, Horuz A (1996) Sulu ham tavuk gübresinin tarımda organik gübre olarak değerlendirilmesi. Ondokuz Mayıs Üniversitesi Dergisi 11(2): 117-125.

Lindsay WL, Norvell WA (1978) Development of a DTPA soil test for Zinc, Iron, Manganese and Copper. Soil science society of America journal 42(3): 421-428.

McGuire RG (1992) Reporting of objective color measurements. HortScience 27: 1254-1255.

Olsen SR, Sommers EL (1982) Phosporus soluble in sodium bicarbonate, Methods of Soil Analysis, Part 2, Chemical and Microbiological Properties. Edit: A.L. Page, P.H. Miller, D.R. Keeney 404-430.

Sönmez İ, Maltaş AŞ, Sarıkaya HŞ, Doğan A, Kaplan M (2019) Tavuk gübresi uygulamalarının domates (Solanum lycopersicum L.) gelişimi ve verim üzerine etkilerinin belirlenmesi. Mediterranean Agricultural Sciences 32(1): 101-107.

Şahin S, Altunal N (2008) Etlik Piliç Dışkılarının Gübre Olarak Değerlendirilmesi ve Önemi, Veteriner Tavukçuluk Derneği Dergisi 6(3): 6-7.

Şeker C, Karakaplan S (1999) Konya ovasında toprak özellikleri ile kırılma değerleri arasındaki ilişkiler. Journal of Agriculture and Forestry 29: 190.

Şensoy S, Abak K, Daşgan HY (1996) Eşdeğer Miktarda Mineral ve Organik Gübre Uygulamalarının Marulda Nitrat Birikimi, Verim ve Kaliteye Etkileri. GAP I. Sebze Tarımı Sempozyumu, Şanlıurfa.

Tavalı İE, Uz İ, Orman Ş (2014). Vermikompost ve tavuk gübresinin yazlık kabağın (Cucurbita pepo L. cv. Sakız) verim ve kalitesi ile toprağın bazı kimyasal özellikleri üzerine etkileri. Mediterranean Agricultural Sciences 27(2): 119-124.

Y1lmaz E, Alagöz Z (2010) Effects of short-term amendments of farmyard manure on some soil properties in the Mediterranean Region-Turkey Journal of Food Agriculture \& Environment 8: 859862 . 